(C) 1982. The Genetical Society of Great Britain

\title{
SELECTION AT THE ALCOHOL DEHYDROGENASE LOCUS OF THE OLIVE FRUIT FLY DACUS OLEAE UNDER ARTIFICIAL REARING
}

\author{
E. ZOUROS, ${ }^{*} \ddagger$ M. LOUKAS, $†$ A. ECONOMOPOULOS* and B. MAZOMENOS* \\ * Laboratory of Entomology, Biology Department, "Demokritos" Nuclear Research \\ Center, Aghia Paraskevi, Attiki, Greece; † Department of Genetics, Agricultural College \\ of Athens, Votanicos, Athens, Greece; $\ddagger$ On leave of absence from Department of \\ Biology, Dalhousie University, Halifax, Nova Scotia B3H $4 \mathrm{~J} 1$.
}

Received 17.viii.81

\section{SUMMARY}

In colonies of the olive fruit fly Dacus oleae maintained on an artificial substrate, an allele of the $\mathrm{ADH}$ locus whose frequency in natural populations is about 1 per cent increases in frequency to about 40 per cent within 6 generations of artificial rearing; the allele most common in natural populations suffers a compensatory decrease from 65 per cent to 30 per cent; a third allele is only slightly affected. This rapid genetic change coincides with an initial negative population growth rate followed by gradually increasing rates, an indication that the selection associated with this change has a toll on the colony's growth. Estimation of relative fitnesses shows that under artificial rearing, heterozygotes are on avera _ twenty times as fit as homozygotes. These are probably the largest selection differentials reported for allozymes, and are comparable only to differentials for tolerance to heavy metals in plants. The hypothesis of linkages of the ADH alleles with other genetic elements (e.g., chromosomal inversions), which are the targets of selection, cannot be excluded. The study demonstrates the types of selection pressures that may operate on newly established colonies of "domesticated" insects and the genetic changes that may result from them.

\section{INTRODUCTION}

IT is a well established phenomenon that natural populations of plants and animals contain large amounts of genetic variation. A certain amount of this variation may be transient, its fate governed by mutation input and genetic drift. But a substantial amount of it may represent the outcome of some form of balancing selection acting on the population. The equilibrium frequencies of polymorphisms of the latter type (balanced polymorphisms) are presumably determined by the conditions under which the population lives. Alteration of these conditions may bring new selection forces on the population, with the result that the population is driven to a new genetic equilibrium.

This phenomenon of genetic change is expected to occur when natural populations of insects are introduced in the laboratory. One might study the process of adaptation to the new environment by comparing wild and laboratory populations with respect to such characters as viability, fecundity, ability to disperse, etc. Although changes in these characters represent the "obvious" product of adaptation, they themselves are the result of more subtle genetic changes. Ideally, one would like to trace the process of adaptation down to the level of the individual gene.

Here we report an attempt in this direction. Our model organism is the olive fruit fly Dacus oleae, a major agricultural pest in Mediterranean 
countries. The fly has been successfully reared in the laboratory for many years and its biology under wild and laboratory conditions has been studied in considerable detail (see Economopoulos and Zervas, 1981, for review). Our model gene is the alcohol dehydrogenase locus (ADH; EC 1.1.1.1). Previous work with several species of Drosophila has clearly shown that environmental conditions drastically affect the allele frequencies at this locus (see, for example, Clarke, 1975).

An electrophoretic comparison of wild and laboratory-reared populations of Dacus oleae was first attempted by Bush and Kitto (1979) who examined two wild and one laboratory populations for twenty two enzyme loci. Tsakas and Zouros (1980) examined two laboratory populations and twelve natural populations for two esterase loci. Following the same line of research, we describe in this study the electrophoretic patterns of the various $\mathrm{ADH}$ genotypes of Dacus oleae, and report on the changes of allelic frequencies in five laboratory colonies founded by individuals from different natural populations. From the consistency in the pattern of change of allelic frequency we argue that strong selection pressures operate on the $\mathrm{ADH}$ locus (or the segment of the genome marked by it), and proceed to estimate relative fitnesses for the various $\mathrm{ADH}$ genotypes under laboratory conditions and compare them with similar estimates from other allozyme studies. Finally, we use the estimated fitnesses to compute the genetic load associated with the $\mathrm{ADH}$ locus during adaptation in the artificial environment. It will be shown that the load is most heavy in the very first generations following introduction in the laboratory and, thus, coincides with a drastic reduction in population size, which invariably marks the early stage of colonization.

Our results have an obvious bearing on the much debated question concerning the adaptive significance of enzyme polymorphisms, but, also, provide an insight into the genetic changes that may occur in mass cultures of economically important insects.

\section{MATERIAL AND METHODS}

The material for this work came from five laboratory colonies and from samples of the wild populations from which the colonies were established.

The first colony (Marathon I) was established in 1964 from flies collected from an olive tree orchard near the village of Marathon, Attica, Greece. The actual number of founding individuals is unknown but must have been larger than a hundred. The $\mathrm{ADH}$ allele frequency distribution at the time of the initiation of the colony is not known. The first electrophoretic survey of the colony occurred in November, 1979 when the colony was approximately 180 generations old (under laboratory conditions a generation time is about a month). Two more samples were analysed, at generations 200 and 208.

The second colony was established in November, 1978, with a sample of 10,000 to 15,000 flies collected from the Tatoi orchard in Attica, Greece. Again, the input $\mathrm{ADH}$ frequencies were not obtained at the time of the initiation of the colony. These frequencies were estimated from a sample collected from the same orchard one year later. Electrophoretic scores were obtained at generations $4,12,15$ and 18 . 
The third colony was established in November, 1979, again with a sample of the same size as the Tatoi colony. The flies were collected from an orchard in a small island called Aghia Triada, a few hundred meters off the island of Euboea, Greece. A sample of 200 files from the founder population was used to obtain estimates of the $\mathrm{ADH}$ allele frequencies at the start of the colony. The gene frequencies in the colony were monitored by taking samples every generation till the sixth generation; an additional sample was taken in generation 12 . The wild population was sampled again a year after the initiation of the colony.

In November, 1980 we sampled the natural population of the orchard from which the Marathon I colony was established. Part of the sample was analysed to provide estimates of gene frequencies in the wild population, and part was kept in the laboratory to initiate a new colony (Marathon II) which was sampled after two generations of artificial rearing.

A similar experiment was carried out in January, 1981. Several thousand flies were collected from an orchard near the town of Eretria, in the island of Euboea, Greece. Part of this sample was analysed for the estimation of gene frequencies in the wild population and the remainder provided the founder population of a colony which was examined again after two generations.

$\mathrm{ADH}$ allozymes were resolved by starch gel electrophoresis using Poulik's (1957) discontinuous buffer system. Gel slabs of 10 per cent in starch and of $0.5 \times 18 \times 20 \mathrm{~cm}$ in dimensions were run at $500 \mathrm{~V} / 150 \mathrm{~mA}$ for about two hours. The cathodal part of the gel was stained for ADH using isopropanol as a substrate. The highest concentration of $\mathrm{ADH}$ was found in the pupa and, therefore, this was the insect stage used for electrophoresis.

The technique for the mass-rearing of the olive fruit fly in the laboratory has been described in detail by Tsitsipis (1977), and can be outlined as follows. Flies emerging from infested olives are kept in $1 \times 0.3 \times 0.4 \mathrm{~m}$ cages and fed an artificial diet consisting of yeast hydrolyzate, sucrose and dry egg yolk $(1: 4: 0 \cdot 3)$, and 0.05 per cent kanamycin or streptomycin sulfate as antibiotic. Thin cone-shaped layers of cerosin are introduced into the cage and used by the females as oviposition surfaces. The eggs are then washed off, incubated for about $24 \mathrm{~h}$ in 0.3 per cent propionic acid and transferred onto the surface of an artificial larval food medium which is made of $5 \mathrm{ml}$ of water, $30 \mathrm{~g}$ of cellulose powder, $7.5 \mathrm{~g}$ brewers yeast, $3 \mathrm{~g}$ soy hydrolyzate enzymatic, $2 \mathrm{~g}$ sucrose, $2 \mathrm{ml}$ olive oil, $0.75 \mathrm{ml}$ Tween-80, $0.05 \mathrm{~g}$ potassium sorbate, $0.2 \mathrm{~g}$ nipagin, and $3 \mathrm{ml} 2 \mathrm{~N} \mathrm{HCl}$. Hatching larvae burrow into the food and emerge again when ready to pupate. At this stage they "jump" off the food tray and are collected in trays of saw dust where they pupate. Before hatching the pupae are introduced into adult population cages to complete one cycle of artificial rearing.

\section{Results}

\section{(i) The ADH allozymes of Dacus oleae}

The ADH zymograms of Dacus oleae are almost identical with those of the seaweed fly Coelopa frigida, which have been recently described by Day and Buckley (1980). As in the case of the seaweed fly, we have 
obtained six distinct allozyme patterns (fig. 1). This pattern of variation was shown by Day and Buckley to be consistent with three alleles segregating at one locus. The three-banded patterns represent the three types of homozygotes; the three multiply-banded patterns represent the three types of heterozygotes. Note that in each heterozygote pattern the slowest and fastest bands have the same mobilities as the slowest and fastest bands of the corresponding homozygotes. We have used the letters $S, I$ and $F$ for allele designation (slow, intermediate and fast mobilities, respectively).

This pattern of electrophoretic variation can be explained by assuming a dimeric structure for the $\mathrm{ADH}$ molecule, with each monomer either in the NAD-bound or non-NAD-bound state. This explanation, which has been confirmed in Drosophila (Schwartz et al. 1975), predicts three bands for homozygotes and nine bands for heterozygotes. Whereas homozygotes appeared always as three-banded, not all nine bands can be separated in the heterozygotes. This also appears to be the case with the seaweed fly.

\section{(ii) Allele frequencies in natural and laboratory populations}

In table 1 we give the frequencies (with their standard errors) of the $\mathrm{ADH}$ alleles in the five colonies at various generations after establishment of the colony. In the same table we give the frequencies in the wild populations $(T=0)$.

Several points of interest emerge from the table. First, the allelic frequencies appear to be the same in all four natural populations. Basically,

\section{TABLE 1}

Allele frequency changes at the ADH locus of Dacus oleae under artificial rearing. Standard errors are given in parenthesis. $\mathrm{T}$ is the number of generations in the laboratory, $\mathrm{N}$ is the sample size, and $\mathrm{F}, \mathrm{I}$ and $\mathrm{S}$ stand for the three alleles

\begin{tabular}{|c|c|c|c|c|c|}
\hline \multirow{2}{*}{ Colony } & \multirow[b]{2}{*}{$T$} & \multirow[b]{2}{*}{$N$} & \multicolumn{3}{|c|}{ 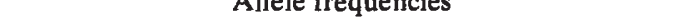 } \\
\hline & & & $S$ & $I$ & $F$ \\
\hline Marathon I & $\begin{array}{l}180 \\
200 \\
208\end{array}$ & $\begin{array}{l}202 \\
142 \\
207\end{array}$ & $\begin{array}{l}0.398(0 \cdot 024) \\
0 \cdot 377(0 \cdot 029) \\
0.384(0.024)\end{array}$ & $\begin{array}{l}0 \cdot 114(0 \cdot 016) \\
0 \cdot 158(0 \cdot 022) \\
0 \cdot 164(0 \cdot 018)\end{array}$ & $\begin{array}{l}0.488(0.025) \\
0.465(0.030) \\
0.452(0.024)\end{array}$ \\
\hline Tatoi & $\begin{array}{r}0 \\
4 \\
12 \\
15 \\
18\end{array}$ & $\begin{array}{l}121 \\
213 \\
197 \\
210 \\
139\end{array}$ & $\begin{array}{l}0.636(0.031) \\
0.399(0.024) \\
0.360(0.024) \\
0.355(0.023) \\
0.360(0.029)\end{array}$ & $\begin{array}{l}0.025(0 \cdot 010) \\
0 \cdot 235(0 \cdot 020) \\
0 \cdot 320(0 \cdot 023) \\
0 \cdot 312(0 \cdot 023) \\
0 \cdot 295(0 \cdot 027)\end{array}$ & $\begin{array}{l}0.339(0.030) \\
0.366(0.023) \\
0.320(0.023) \\
0.333(0.023) \\
0.345(0.028)\end{array}$ \\
\hline Aghia Triada & $\begin{array}{r}0 \\
1 \\
2 \\
3 \\
4 \\
5 \\
6 \\
12 \\
0\end{array}$ & $\begin{array}{l}200 \\
209 \\
213 \\
203 \\
200 \\
174 \\
207 \\
220 \\
207\end{array}$ & $\begin{array}{l}0.610(0.024) \\
0.744(0.021) \\
0.430(0.024) \\
0.394(0.024) \\
0.317(0.023) \\
0.287(0.024) \\
0.280(0.022) \\
0.277(0.021) \\
0.643(0.024)\end{array}$ & $\begin{array}{l}0.005(0.003) \\
0.014(0.005) \\
0.244(0.021) \\
0.266(0.022) \\
0.357(0.024) \\
0.348(0.025) \\
0.321(0.023) \\
0.336(0.022) \\
0.007(0.004)\end{array}$ & $\begin{array}{l}0.385(0.024) \\
0.242(0.021) \\
0.326(0.023) \\
0.340(0.023) \\
0.325(0.023) \\
0.365(0.026) \\
0.398(0.024) \\
0.386(0.023) \\
0.349(0.023)\end{array}$ \\
\hline Marathon II & $\begin{array}{l}0 \\
2\end{array}$ & $\begin{array}{l}193 \\
134\end{array}$ & $\begin{array}{l}0.692(0.023) \\
0.243(0.026)\end{array}$ & $\begin{array}{l}0.008(0 \cdot 004) \\
0.351(0 \cdot 029)\end{array}$ & $\begin{array}{l}0.301(0.023) \\
0.407(0.030)\end{array}$ \\
\hline Eretria & $\begin{array}{l}0 \\
2\end{array}$ & $\begin{array}{l}136 \\
175\end{array}$ & $\begin{array}{l}0.647(0.030) \\
0.381(0.026)\end{array}$ & $\begin{array}{l}0.004(0 \cdot 004) \\
0 \cdot 300(0 \cdot 024)\end{array}$ & $\begin{array}{l}0 \cdot 346(0 \cdot 029) \\
0 \cdot 319(0 \cdot 025)\end{array}$ \\
\hline
\end{tabular}




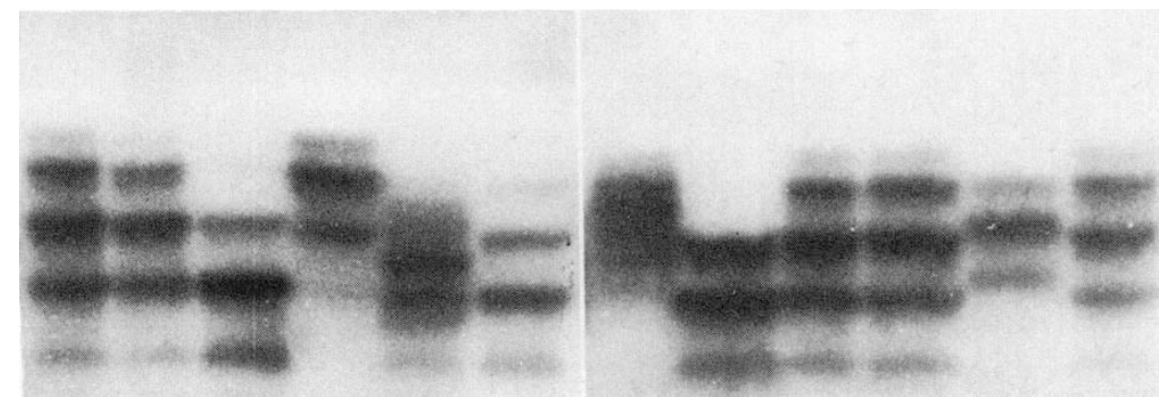

FIG. 1.-ADH zymograms of Dacus oleae. Wells 3,6 and 8 are $S S$, well 4 is $F F$, well 11 is $I I$, well 5 is $S I$, well 7 is $I F$, and wells $1,2,9,10,12$ are $S F$. 
two alleles exist in these populations, but a third allele $(I)$ is present in all populations in very low frequencies. This allele appeared two or three times in each sample and always in the heterozygote form. Second, the allelic frequencies in the colonies are quite different from those in natural populations: in all colonies there has been a marked increase of the $I$ allele followed by a compensatory decrease of allele $S$; the frequency of $F$ remained more or less unchanged. Third, the allelic frequencies changed very rapidly, and within a few generations an equilibrium was reached with all three alleles present in relatively high frequencies.

The behaviour of the ADH polymorphism appears to be the same in all five colonies. In the colonies of Eretria and Aghia Triada the frequency of the $I$ allele increased from 20 -fold to 70 -fold within the first two generations. For the Tatoi colony we have no frequency readings for the first three generations, but after four generations of artificial rearing the frequency of allele $I$ was ten times higher than in the wild population from which the colony was established. The Marathon I colony differs from the others in that the frequency of the $I$ allele has increased to 0.16 after 200 generations. We have no way of knowing whether this increase occurred within the first few generations in the laboratory or is the result of a gradual process. Still, this is a much higher frequency than is found in the natural population from which the colony was derived. We, therefore, conclude that, in spite of some quantitative differences between colonies, the genetic response to artificial rearing has been the same and is marked by a dramatic increase in the frequency of an $\mathrm{ADH}$ allele, which under natural conditions is kept in very low levels.

\section{(iii) Estimation of relative fitnesses}

The rapid change of allelic frequencies are indicative of strong selection differentials among the six ADH genotypes. Estimates of these differentials were obtained from the colonies of Tatoi and Aghia Triada by the method of maximum likelihood as described in detail by DuMouchel and Anderson (1968).

Basically, the method consists in finding a vector of relative fitnesses that maximises the logarithm of the function

$$
L=\prod_{i, t} p_{i, t}^{x_{i, t}}
$$

where $p$ stands for expected gene frequency, $x$ for observed number of alleles in the sample, $i$ for alleles (in our case $i=1,2,3$ ) and $t$ for the number of generations since initiation of the colony. The model assumes discrete generations and constant fitnesses, and also, that the population size is large so that actual population frequencies are not very different from expected frequencies. Under these assumptions

$$
p_{i, t}=\frac{p_{i, t-1} \sum_{i}\left(p_{i, t-1} W_{i j}\right)}{\bar{W}_{t-1}}
$$

where $W_{i j}$ is the fitness of genotype $A_{i} A_{i}$ and

$$
\bar{W}_{t-1}=\sum_{i, j} p_{i, t-1} p_{j, t-1} W_{i j}
$$


There are two methods one may use to estimate $p_{i, r}$. In the first method one ignores gene frequencies obtained from samples before generation $t$. Gene frequencies of the first generation $\left(p_{i, 1}\right)$ are expressed as functions of the initial frequencies $\left(p_{i, 0}\right)$ and the unknown fitness vector $\left(W_{i j}\right)$, according to equations (2) and (3). These first-generation frequencies are in turn used to obtain an expression of the gene frequencies of the second generation, and so on until generation $t$. Thus, $p_{i, t}$ is ultimately expressed as a function of $p_{i, 0}, W_{i j}$, and $t$, the number of generations since the initiation of the colony. In the second method one proceeds as in the first method except that instead of generation zero, one departs from the latest generation for which sample estimates of gene frequencies exist. Thus, if the population was sampled at generation $t-n$, then $p_{i, t}$ will be a function of $p_{i, t-n}, W_{i j}$, and $n$, the number of generations since the last sample. If samples are taken every generation (as was the case for the first six generations of colony Aghia Triada), then the expected gene frequencies at each generation are expressed as functions of the observed gene frequencies in the proceeding generation.

There can be several reasons for using one or the other method. DuMouchel and Anderson recommend the first method provided that the initial frequencies are accurately estimated and the population size remains large throughout the experiment. Neither condition was true in our experiments. The initial samples were relatively small and the sizes of the colonies during the first and second generations were not more than 3000 even though the founder populations were relatively large. From these generations we were sampling for electrophoresis almost a tenth of the population, so that our sampling estimates must be rather close to actual population frequencies. In addition, it appears that the second approach of estimation is more appropriate if most of the gene frequency change occurs within the first few generations. Obviously, much larger samples will be required if the fitnesses have to be estimated from samples of later generations, when the frequencies change at a much slower rate. Also, the assumption of non-overlapping generations is less critical when data from the first generations are used (when an accurate monitoring of the number of generations is possible). For these reasons we have used the second method which makes use of all samples. The first method was also tried. It produced very similar vectors of fitness estimates, but ones which gave a poorer fit to the data. In addition to the maximum likelihood method, we tried the method of chi-square minimization and minimization of the sum of squares of the differences between observed and expected frequencies. Again, the estimates were similar to maximum likelihood estimates, but provided a less satisfactory fit to the data.

The likelihood equations were solved by reiteration in the computer using the method of steepest ascent. The results are given in table 2. As expected from the pattern of gene frequency change, very large selection differentials exist between ADH genotypes under the conditions of artificial rearing. Another observation is that the fitness of heterozygotes greatly exceeds the fitness of homozygotes. Taking arithmetic means over genotypes and over colonies one concludes that, on average, the fitness of heterozygotes is twenty times as high as the fitness of homozygotes. 


\section{TABLE 2}

Estimates of relative fitnesses of the ADH genotypes under artificial rearing. The value one was assigned to the genotype with the highest fitness

\begin{tabular}{ccc} 
& \multicolumn{2}{c}{ Fitness } \\
Genotype & Tatoi & Aghia Triada \\
SS & $0 \cdot 085$ & $0 \cdot 071$ \\
II & $0 \cdot 025$ & $0 \cdot 019$ \\
$F F$ & $0 \cdot 051$ & $0 \cdot 021$ \\
SI & 1 & $0 \cdot 924$ \\
SF & $0 \cdot 891$ & $0 \cdot 255$ \\
IF & 0.964 & 1
\end{tabular}

\section{(iv) Comparison of observed and expected frequencies}

The fitness estimates of table 2 may be used to calculate expected gene frequencies. These are shown in table 3, and the results from the chi-square tests for the goodness of fit between observed and expected frequencies are given in the same table. The degrees of freedom in these tests are:

$$
D F=1+n(k-1)-k(k+1) / 2
$$

where $k$ is the number of alleles and $n$ is the number of generations sampled (DuMouchel and Anderson, 1968). The fit is barely satisfactory for the Tatoi population, but it is poor for the Aghia Triada population.

The lack of a satisfactory statistical fit between observed and expected gene frequencies is most likely due to the small size of the colonies during the crucial first generations. These can be little doubt that during this period, random drift was of sufficient magnitude to produce large random fluctuations around the trajectories predicted by the selection equations. This makes it very difficult to arrive at fitness estimates that will produce

\section{TABLE 3}

Observed and expected (in parenthesis) allelic frequencies for the colonies of Tatoi and Aghia Triada. Expected frequencies were calculated from the selection coefficients of table 2. The results from the chi-square test of goodness of fit are as follows; Tatoi: $\mathrm{x}^{2}=7 \cdot 59, \mathrm{DF}=3$, $\mathrm{P}=0.055 ;$ Aghia Triada: $\mathrm{x}^{2}=320.27, \mathrm{DF}=9, \mathrm{P}=0$. Symbolism as in table 1

\begin{tabular}{|c|c|c|c|c|}
\hline \multirow[b]{2}{*}{ Colony } & \multirow[b]{2}{*}{$T$} & \multicolumn{3}{|c|}{ Allele frequencies } \\
\hline & & $\boldsymbol{S}$ & $I$ & $F$ \\
\hline Tatoi & $\begin{array}{r}0 \\
4 \\
12 \\
15 \\
18\end{array}$ & $\begin{array}{l}0.636(-) \\
0.399(0.408) \\
0.360(0.342) \\
0.355(0.342) \\
0.360(0.342)\end{array}$ & $\begin{array}{l}0.025(-) \\
0.235(0 \cdot 206) \\
0.320(0.344) \\
0.312(0.344) \\
0.295(0.344)\end{array}$ & $\begin{array}{l}0.339(-) \\
0.366(0.386) \\
0.320(0.314) \\
0.333(0.314) \\
0.345(0.314)\end{array}$ \\
\hline Aghia Triada & $\begin{array}{r}0 \\
1 \\
2 \\
3 \\
4 \\
4 \\
5 \\
6 \\
12\end{array}$ & $\begin{array}{l}0.610(-) \\
0.744(0.561) \\
0.430(0.486) \\
0.394(0.367) \\
0.317(0.305) \\
0.287(0.285) \\
0.280(0.276) \\
0.277(0.246)\end{array}$ & $\begin{array}{l}0.005(-) \\
0.014(0.030) \\
0.244(0.140) \\
0.266(0.337) \\
0.357(0.435) \\
0.348(0.457) \\
0.321(0.461) \\
0.336(0.463)\end{array}$ & $\begin{array}{l}0.385(-) \\
0.242(0.409) \\
0.326(0.374) \\
0.340(0.296) \\
0.325(0.260) \\
0.365(0.257) \\
0.398(0.262) \\
0.386(0.290)\end{array}$ \\
\hline
\end{tabular}


a satisfactory fit between observed and expected frequencies. Schaffer et al. (1977) have developed a method which takes into account the effect of random drift and allows for the detection of selection from data obtained from a series of generations of laboratory populations. But their method is suitable only for directional selection, and, therefore, is not applicable in our case (where we are clearly dealing with balancing selection). In addition, our problem is not so much to prove the presence of selection (a mere inspection of table 1 is adequate for this purpose), but rather to produce a fitness vector that will adequately describe the process of gene frequency change.

Judging from the fact that the fit is more satisfactory for the Tatoi colony, one may be inclined to accept its fitness vector as the one closer to the "true" fitness vector. However, it is important to note that the two vectors are in fact very similar. Although a formal statistical comparison is possible, it is hardly necessary in this case. It will be sufficient to note that with the exception of genotype $S F$, corresponding estimates are very close to each other, and the rankings within each vector are nearly identical (Kendall's non-parametric rank correlation coefficient is $\tau=0.87, P(\tau=$ $0)=0.01$; and the regression of one vector against the other produces a slope $b=0.92, P(b=1)=0 \cdot 80)$. This close similarity of the two fitness vectors constitutes strong evidence for the overwhelming significance of selection over random drift in producing the results we have observed.

\section{(v) Stability and equilibrium gene frequencies}

The fitness vectors of table 2 can be used to obtain equilibrium gene frequencies and to test for the stability of these equilibria (Crow and Kimura, 1970, p. 275-277).

For the Tatoi colony we have $\Delta_{S}=0.822, \Delta_{I}=0.827, \Delta_{F}=0.753$ and $T=-1.646$, where $\Delta_{i}$ is the determinant of the fitness matrix after replacing each element of column $i$ by one, and $T=W_{S S}-2 W_{S F}+W_{F F}$. These satisfy the necessary and sufficient conditions for a stable equilibrium, and produce the equilibrium frequencies: $\hat{p}_{S}=0 \cdot 342, \hat{p}_{I}=0 \cdot 344, \hat{p}_{F}=0 \cdot 313$. For the Aghia Triada colony the corresponding values are: $\Delta_{S}=0 \cdot 155, \Delta_{I}=0 \cdot 337$, $\Delta_{F}=0.231, T=-0.418, \hat{p}_{S}=0 \cdot 215, \hat{p}_{I}=0 \cdot 466, \hat{p}_{F}=0.319$.

In fig. 2 we present graphically the evolution of the ADH frequencies in the two colonies. A triallelic system can be represented as a point in an equilateral triangle whose height is unity; the allelic frequencies are given by the distances of the point from the three sides. In the figure, the equilibrium point is shown by a star and is joined with the initial point by the trajectory predicted from the fitness values of table 2 . The sample points are also shown in the figure. The figure serves to illustrate the steep ascent to equilibrium, which is completed within a few generations. It also provides an appreciation of the deviation of observed from expected points.

\section{(vi) Population "bottle-necks" and genetic loads}

It was mentioned previously that the number of individuals in the colony drops drastically during the first and second generations. In subsequent generations there is a steady increase in population size. Since most of the change in allelic frequency also occurs during the first two generations, 

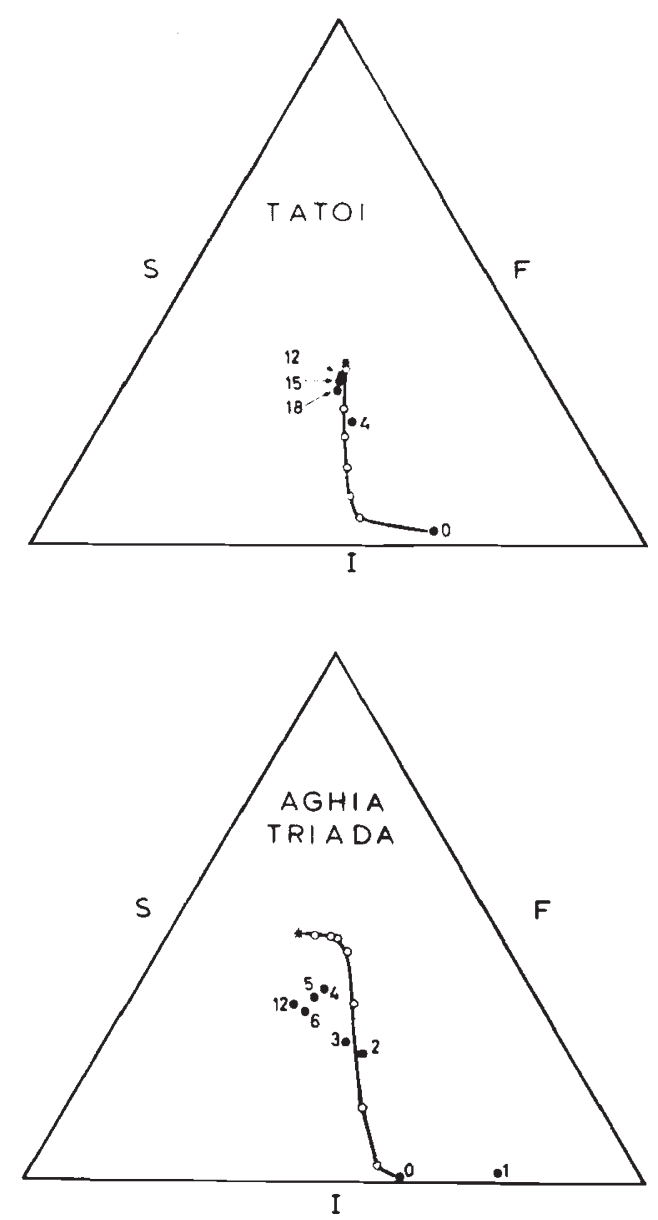

FIG. 2.-The changes of the ADH allele frequencies in two colonies. The frequencies of the three alleles measured at right angles to the lines labelled as $S, I$, and $F$ determine a point in an equilateral triangle. Filled dots give the observed position of the colony at the shown generation. Open circles are expected positions, and the star is the predicted equilibrium point. The shown expected points are for Tatoi generations 1 to 5 and 12 , and for Aghia Triada 1 to 6 and 12.

one may suspect that there exists a relationship between the two phenomena. One way to formalize this observation is to calculate the genetic load associated with the $\mathrm{ADH}$ locus during the generations before the population has reached equilibrium.

At equilibrium there will be a segregational load, given by $\hat{L}=1-\hat{\bar{W}}$. For the Tatoi population $\hat{L}=0.348$ and for Aghia Triada $\hat{L}=0.472$, suggesting that the ADH polymorphism "costs" the population about one third to one half of its reproductive potential. This is a rather heavy load, and one suspects that given enough time the population will acquire modifier genes whose effect will be to ease the selection pressure at the ADH locus.

The load for any given generation $t$ will be $L_{t}=1-\bar{W}_{t}$. For the generations preceding the equilibrium the quantity of interest will be the ratio 
$L_{t} / \hat{L}$, which measures the load associated with the gene frequency change. This ratio is given in fig. 3 for the first six generations of the Tatoi and for the first five generations of the Aghia Triada colonies. The ratio is plotted against the frequency of the $I$ allele. It can be seen that there is a strong negative correlation between $L_{t} / \hat{L}$ (which may be considered analogous to substitutional load) and the frequency of the $I$ allele. The load is most heavy in the first generations when the size of the colony is smallest.

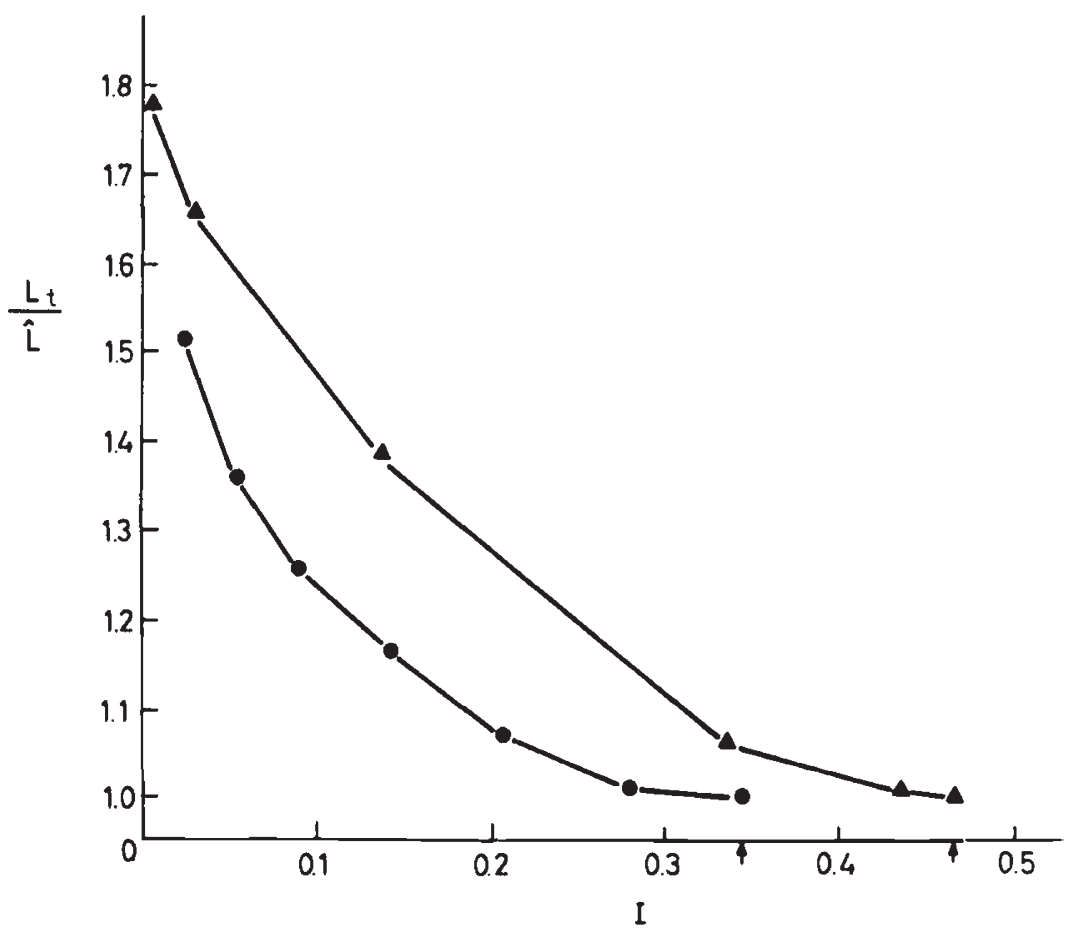

FIG. 3.-The ADH segregation load as a function of allele frequency. Abscissa: the frequency of allele $I$; ordinate the ratio of load over the equilibrium load. Circles and triangles represent the first generations (from left to right) except the last point which is the equilibrium point. Circles are for the Tatoi colony and triangles for the Aghia Triada colony; the arrows mark the equilibrium frequency of allele $I$.

\section{Discussion}

A simple inspection of table 1 makes it clear that strong selection pressures act on the ADH locus (or the segment of the genome it marks) under the conditions developed for the mass culturing of the insect. The evidence for selection comes from the very drastic change of gene frequencies and, also, from the close similarity in the pattern of gene frequency change in five different colonies originating from four different natural populations. Obviously, this genetic response must reflect the fundamental differences that exist between the insect's natural habitat and the rearing conditions in the laboratory. 
TABLE 4

Estimates of selection coefficients of various genetic traits

\begin{tabular}{|c|c|c|c|}
\hline Species & Trait & $\begin{array}{l}\text { Selection } \\
\text { Coefficient }\end{array}$ & $\begin{array}{l}\text { Source an } \\
\text { Comment }\end{array}$ \\
\hline $\begin{array}{l}\text { Drosophila polymorpha } \\
\text { Maniolia jurtina } \\
\text { Biston betularia }\end{array}$ & $\begin{array}{l}\text { Coloration of abdomen } \\
\text { Number of spots on wings } \\
\text { Wing mechanism }\end{array}$ & $\begin{array}{l}0.61 \\
0.71 \\
0.60\end{array}$ & $\begin{array}{l}(1) \\
(2) \\
(3)\end{array}$ \\
\hline $\begin{array}{l}\text { Agrostis tenuis } \\
\text { in mine } \\
\text { in pasture }\end{array}$ & Tolerance to metals & $\begin{array}{l}0.95 \\
0.05\end{array}$ & $\begin{array}{l}(4) \\
(4)\end{array}$ \\
\hline $\begin{array}{l}\text { Anthoxanthum odoratum } \\
\text { in mine } \\
\text { in pasture }\end{array}$ & Tolerance to metals & $\begin{array}{l}0.99 \\
0 \cdot 30\end{array}$ & $\begin{array}{l}(4) \\
(4)\end{array}$ \\
\hline $\begin{array}{l}\text { Drosophila pseudoobscura } \\
\text { Drosophila pseudoobscura }\end{array}$ & $\begin{array}{l}\text { Inversion polymorphism } \\
\text { Inversion polymorphism }\end{array}$ & $\begin{array}{l}0.77 \\
0 \cdot 35\end{array}$ & $\begin{array}{l}(5) \\
(6)\end{array}$ \\
\hline $\begin{array}{l}\text { Hordeum vulgare } \\
\text { Hordeum vulgare } \\
\text { Hordeum vulgare }\end{array}$ & $\begin{array}{l}\text { Est-A } \\
\text { Est }-\mathrm{B} \\
\text { Est-C }\end{array}$ & $\begin{array}{l}0 \cdot 69 \\
0 \cdot 11 \\
0 \cdot 31\end{array}$ & $\begin{array}{l}(7) \\
(7) \\
(7)\end{array}$ \\
\hline Zoarces viviparus & Est-III & 0.06 & (8) \\
\hline Drosophila melanogaster & $\mathrm{ADH}$ & $0 \cdot 13$ & (9) \\
\hline $\begin{array}{l}\text { Drosophila willistoni } \\
\text { group }\end{array}$ & $\mathrm{MDH}$ & $0 \cdot 25$ & (10) \\
\hline $\begin{array}{l}\text { Drosophila pseudoobscura } \\
\text { Drosophila pseudoobscura } \\
\text { Drosophila pseudoobscura }\end{array}$ & $\begin{array}{l}\text { MDH } \\
\text { ODH } \\
\text { Est -5 }\end{array}$ & $\begin{array}{l}0 \cdot 10 \\
0 \cdot 10 \\
0 \cdot 08\end{array}$ & $\begin{array}{l}(11) \\
(11) \\
(11)\end{array}$ \\
\hline Dacus oleae & $\mathrm{ADH}$ & 0.95 & (12) \\
\hline
\end{tabular}

(1) Da Cuhna (1949).

(2) Dowdeswell (1961).

(3) Clarke and Sheppard (1966).

(4) Jain and Bradshaw (1966).

(5) Wright and Dobzhansky (1946); mean fitness of homozygotes compared to the mean fitness of the heterozygotes.

(6) Dobzhansky and Pavlovsky (1953); as in (5).

(7) Clegg et al. (1978); the fitness of a genotype was calculated as the geometric mean of viability and fertility, and the average fitness of all homozygotes was compared to the average fitness of all heterozygotes.

(8) Christiansen et al. (1977).

(9) Original data from van Delden et al. (1978), estimates by Mukai and Yamazaki (1980); grand mean of all selection coefficients.

(10) Original data from Ayala and Anderson (1973), estimates by Mukai and Yamazaki (1980); grand mean of all selection coefficients in three species.

(11) Original data from Fontdevila et al. (1975), estimates by Mukai and Yamazaki (1980); as in (9).

(12) This study; mean of homozygotes from both colonies compared to mean of heterozygotes.

The degree and nature of selection is quantified in table 2, where we give estimates of selection differentials for the six $\mathrm{ADH}$ genotypes. We have already commented on the similarity of the two fitness vectors, which is in itself evidence for the overwhelming importance of selection over random drift as the force determining gene frequencies in our colonies. It is of some interest to compare these selection coefficients with similar estimates from other studies. This is done in table 4, where we give selection coefficients for a representative set of genetic traits. It can be seen that 
selection coefficients for the ADH locus of Dacus oleae under artificial rearing far exceed the selection coefficients for enzyme polymorphisms of laboratory populations of Drosophila, and even appear to be larger than the selection coefficients for barley allozymes, which, because of the high degree of selfing in this species, must almost certainly reflect selection for much larger parts of the genome. The Dacus ADH selection pressure also appears to be heavier than that estimated for inversion polymorphisms and for some well known phenotypic characters, and are only comparable to selection pressures suffered by plants growing on soils contaminated by heavy metals.

This amount of selection pressure cannot possibly operate in the natural populations of the insect. It appears when the organism is introduced in an environment which has never been a part of its evolutionary history, and which, apparently, represents a radical deviation from its natural way of life. At present, we have no idea at what stage of the insect's life cycle the selection pressure is most intense. Indirect observations suggest that the initial decline in population size could be attributed to a large extent to the refusal of most females to use the artificial medium for oviposition. Another factor is reduced larval growth and larval survival in the artificial medium.

Is it possible that $\mathrm{ADH}$ variation influences the oviposition behaviour of the insect? Some behavioural studies implicating the ADH polymorphism have appeared recently. King et al. (1976), and Richmond and Gerking (1979) have studied oviposition preference among sites containing different amounts of alcohol in various species of Drosophila. Some correlation appears to exist between alcohol dehydrogenase activity in the fly and the level of alcohol in the preferred (or avoided) oviposition site, but neither the nature nor the extent of this correlation is understood at present. Oviposition is only one character that may be affected by alcohols in the environment. Several studies (e.g., McKenzie and Parsons, 1972; Starmer et al., 1977) have shown that environmental alcohols may have different effects on the dispersal and longevity of related species and may, ultimately, contribute to the spatial distribution of competing species. The alcohol preference behaviour in larvae of Drosophila melanogaster was studied by Gelfand and McDonald (1980) who used for this purpose homozygous lines for the fast, slow and null alleles at the ADH locus. These genotypes have different alcohol dehydrogenase levels (fast $>$ slow $>$ null). Gelfand and McDonald observed that alcohol concentrations below 10 per cent did not cause a differential response among $\mathrm{ADH}$ genotypes, but such a response was observed at higher levels of alcohol concentration. At such concentrations, genotypes with lower alcohol dehydrogenase levels exhibited a higher degree of avoidance of the alcohol-rich medium.

It may be easier to understand the effect of the synthetic food on the larval viability and growth of the various $\mathrm{ADH}$ genotypes of Dacus oleae. The effect of alcohol content of the medium on the various fitness components of Drosophila melanogaster has been studied in many laboratories and has been shown to vary among $\mathrm{ADH}$ genotypes (e.g., references in van Delden et al., 1978, and Gelfand and McDonald, 1980). These responses correlate well with biochemical studies of partially purified alcohol dehydrogenase preparations from different ADH genotypes (Day et $a l ., 1974 a, b)$. Thus, a considerable amount of information now exists 
which relates fitness performance, ecological patterns and competition outcomes to a single enzyme locus, $\mathrm{ADH}$, whose variation in natural and laboratory populations can be easily and rapidly assessed by electrophoresis. The physiology of the response is understood to a considerable degree, and it is possible to manipulate the organism's environment in such a way as to cause a predictable genetic change.

The cumulative work on the ADH locus in Drosophila has made it possible to think of this locus not merely as another electrophoretic marker, but as a model to trace fitness responses to a single locus level. This claim can be made for only a few other electrophoretically detectable enzyme loci, such as amylase (De Jong et al., 1972) and $\alpha$-glycerophosphate dehydrogenase. The latter enzyme is correlated with flying ability in insects (Kitto and Briggs, 1962; O'Brien and MacIntyre, 1972). Indeed, Bush et al. (1976) reported a dramatic shift in the frequency of $\alpha-G D H$ allele in factory-reared populations of the screwworm fly, Cochliomyia hominivorax, which is apparently part of the cause for its reduced ability for dispersal under natural conditions.

The preceding arguments support the hypothesis that the selection we have observed may be, in all or in part, directed against the ADH locus itself. We cannot, of course, exclude the possibility that selection is not acting at the ADH locus, but at the region of the genome marked by it. This is basically a hypothesis of linkage disequilibrium. One way that such a linkage can be maintained is through chromosomal inversions. Krimbas (1963) has described the mitotic and salivary gland chromosomes of Dacus oleae, but there has been no attempt to study the cytology of the species from the population genetic point of view. Thus, the question of an association of the ADH alleles with inversions remains open. If a gene arrangement polymorphism exists and responds to selection, it must consist of at least three alternative forms, one of which must be associated with the $I$ allele (selected for), one with the $S$ allele (selected against), and the remaining associated with the $F$ allele (behaving as neutral). In Drosophila non-random associations between inversions and electromorphs of enzyme loci included in (or in the proximity of) inversions have been observed in some cases (Prakash and Lewontin, 1968) but not in others (Loukas $e$ t al., 1979). Thus, presence of inversions would not necessarily imply a linkage disequilibrium with $\mathrm{ADH}$ alleles. In addition, we may note from table 4 that the observed selection levels are remarkably high even for inversion polymorphisms.

The abrupt change in ADH allelic frequencies is only one of the many other changes in the biology of the species that occur within a few generations of artificial rearing. We have already commented on the reduction of the colony's size and how it may relate to the ADH frequency changes. Novel characters appearing after the initial decline of population size include a high degree of acceptance of the artificial oviposition surface by females and an increased larval viability and growth in the artificial medium. Some other major differences between laboratory-reared and wild insects include shorter time to sexual maturation of laboratory-reared males (Economopoulos et al., 1971, and Zervas, 1977), earlier occurrence of matings during the photophase (Zervas and Economopoulos, 1981), reduced ability to disperse (Remund et al., 1977 and in press), and high oviposition rates in early age (Economopoulos et al., 1976). Most of these changes have been observed to occur within a short period of time after 
the start of the colony and may or may not be related to the changes at the ADH locus.

Whether selection acts on the ADH locus or on co-segregating blocks of loci, the obvious outcome of the "adaptation" process is to increase the genetic variability in the colonies over and above the levels observed in natural populations. The heterozygosity (obtained a $H=1-\sum p_{i}^{2}$, where $p$ is the allelic frequency) in natural populations is 0.463 (average of the five samples from natural populations shown in table 1). The heterozygosities in the colonies at the latest generation scored are: 0.621 for Marathon I, 0.652 for Marathon II, 0.664 for Tatoi, 0.661 for Aghia Triada, and 0.663 for Eretria. The projected heterozygosities at equilibrium are 0.667 for Tatoi, and 0.635 for Aghia Triada. These values exceed the ones in natural populations by about 50 per cent. Another way of appreciating the increase of heterozygosity in the laboratory is to ask what fraction of the maximum possible heterozygosity value is realized in the field and in the laboratory. The maximum heterozygosity under Hardy-Weinberg conditions (which always hold in our samples) is $H_{\max }=1-(1 / n)$, where $n$ is the number of alleles. In our case $n=3$, giving $H_{\max }=0.667$. We see that in natural populations the heterozygosity is about 70 per cent of the maximum possible, whereas in the laboratory colonies it is, on average, 97 per cent. If one excludes the colony of Marathon I, this value becomes almost 100 per cent.

The increase of heterozygosity in laboratory colonies is not unique to ADH. Tsakas and Zouros (1980) examined the variation at two highly polymorphic esterases of Dacus oleae (Est-A and Est-B) in the Marathon I and Tatoi colonies (the other colonies described here were not yet established at that time) and compared it to the variation in twelve natural populations extending from Spain to Syria. The average heterozygosity in the two colonies was 0.811 for Est-A and 0.652 for Est-B; in the natural populations the averages were 0.725 and 0.556 , respectively. Again, the laboratory colonies had higher degrees of heterozygosity.

The observations from the ADH, Est-A and Est-B loci may suggest that the introduction of the insect into the laboratory has a uniform effect on enzyme loci or the inversion with which they are linked, i.e., to increase overall heterozygosity rather than select for a particular allele or a particular gene arrangement. It may appear somewhat surprising that laboratory populations living in a rather constant environment will retain higher levels of genetic variation than do wild populations, which, presumably, are exposed to a continuously changing environment. But our perception of variation of an organism's environment may be totally different from the perception by the organism itself who, in the wild, may seek and find suitable uniform environments. Another reason for the elevated heterozygosity may be that the overwhelming cause of selection in the laboratory is not the uniformity of the environment, but rather the high degree of competition to which animals are exposed, and which may favour the heterozygotes.

Finally we consider the importance of our findings for the control of the olive fruit fly. The objective of current experimental work on the insect is to develop a methodology for the ultimate replacement of the chemical control of the fly, now in general use around the Mediterranean, with an ecologically less damaging integrated system which will rely heavily on 
non-insecticidal methods (Economopoulos, 1979). For this we need an efficient method for culturing the insect in the laboratory and genetic markers that will facilitate comparisons between laboratory- and wildreared animals for such characters as dispersal, longevity, sexual drive, sensitivity to heat shock, etc. It now appears possible to obtain colonies fixed for the $I$ allele of $A D H$, an allele which in natural populations has a frequency of 0.5 to 1 per cent. This can be done either by modifying the rearing conditions so as to select for the $I$ allele, or, failing that, by a series of pair matings from which only lines fixed for the $I$ allele will be pooled together to establish a new colony.

Furthermore, the ADH locus holds the promise for the development of a "sexing" system, i.e., a technique for obtaining unisexual populations. Such a technique has been developed already in Drosophila melanogaster by Robinson and van Heemert (1981), and consists in the use of a $Y$ chromosome translocation carrying an "active" ADH allele, whereas autosomes carry a "null" allele. In a food supplemented with four per cent alcohol only larvae carrying the active allele, i.e., males, survive. If the method of sterile insect release is going to be applied to Dacus oleae the development of a "sexing" technique will be highly desirable. The production and release of females not only adds to the cost of the operation, but also sterile females retain the habit to open oviposition holes on the olive fruit thus rendering it liable to bacterial and fungal infection.

Acknowledgements. - This work was initiated while E.Z. was the recipient of a research fellowship from the Greek Atomic Energy Commission. He thanks the staff of the.Entomology Department of "Demokritos" Nuclear Research Center for their hospitality. The "Development of Pest Management Systems for Olive Culture Program" of F.A.O. covered part of the chemical expense.

\section{REFERENCES}

AYALA, F., AND ANDERSON, W. W. 1973. Evidence of natural selection in molecular evolution. Nature New Biol., 241, 274-276.

BUSH, G. L., NECK, R. W., AND KITTO, G. B. 1976. Screwworm eradication: inadvertent selection for non-competitive ecotypes during mass rearing. Science, 193, 491-493.

BUSH, G. L., AND KITTO, G. B. 1979. Research on the genetic structure of wild and laboratory strains of olive fly. F.A.O. Report, Development of Pest Management Systems for Olive Culture Program. F.A.O. of the United Nations, Rome.

CHRISTIANSEN, F. B., FRYDENBERG, D., AND SIMONSEN, V. 1977. Genetics of Zoarces populations. X. Selection component analysis of Est-III polymorphism using samples of successive cohorts, Hereditas, 87, 129-150.

CLARKE, B. 1975. The contribution of ecological genetics to evolutionary theory. Detecting the direct effects of natural selection on particular polymorphic loci. Genetics, 79, 101113.

CLARKE, C. A., AND SHEPPARD, P. M. 1966. A local survey of the distribution of industrial melanic forms in the moth Biston betularia and estimates of the selection values of these in an industrial environment. Proc. Roy. Soc. Lond. Ser, B., 165, 424-439.

CLEGG, M. T., KAHLER, A. L., AND ALLARD, R. W. 1978. Estimation of life cycle components of selection in an experimental plant population. Genetics, 89, 765-792.

CROW, J. F., AND KIMURA, M. 1970. An Introduction to Population Genetics Theory. Harper \& Row, New York, Evanston \& London, pp. 275-277.

DA CuHNA, A. B. 1949. Genetic analysis of the polymorphism of color pattern in Drosophila polymorpha. Evolution, 3, 239-251.

DAY, T. H., HILlieR, P. C., AND CLARKE, B. 1974a. Properties of genetically polymorphic isozymes of alcohol dehydrogenase in Drosophila melanogaster. Bioch. Genet., 11, 141153. 
DAY, T. H., Hillier, P. C., AND ClARKE, B. 1974b. The relative quantities and catalytic activities of enzymes produced by alleles at the alcohol dehydrogenase locus in Drosophila melanogaster. Bioch. Genet., 11, 155-165.

DAY, T. H., AND BUCKLEY, P. A. 1980. Alcohol dehydrogenase polymorphism in the seaweed fly, Coelopa frigida. Bioch. Genet., 18, 727-742.

DE JONG, G., HOORN, A. J. W., THÖRIG, G. E. W., AND SCHARLOO, W. 1972, Frequencies of amylase variants in Drosophila melanogaster. Nature, 238, 452-453.

DOBZHANSKY, TH., AND PAVLOVSKY, O. 1953. Intermediate outcome of certain experiments on Drosophila populations. Evolution, 7, 198-210.

DOWDESWELL, W. H. 1961. Experimental studies on natural selection in the butterfly Maniola jurtina. Heredity, 16, 39-52.

DU MOUCHEL, W. H., AND ANDERSON, W. W. 1968. The analysis of selection in experimental populations. Genetics, 58, 435-449.

ECONOMOPOULOS, A. P. 1979. Prospects for the control of Dacus oleae (Gurelin) (Diptera, Tephritidae) by methods that do not involve insecticides. The sterile insect release technique and oflactory and visual traps, integrated approach. International Organization for Biological Control West Parlearctic Regional Section (IOBC/WPRS) Bulletin (1979) $2 / 1,42-49$.

ECONOMOPOULOS, A. P., GIANNAKAKIS, A., TZANAKAKIS, M. E., AND VOYADJOGLOU, A. V. 1971. Reproductive behaviour and physiology of the olive fruit fly. I. Anatomy of the adult rectum. Odors emitted by adults. Ann. Entomol. Soc. Amer., 64, 1112-1116.

ECONOMOPOULOS, A. P., VOYADJOGLOU, A. V., AND GIANNAKAKIS, A. 1976. Reproductive behaviour and physiology of Dacus oleae: fecundity as affected by mating, adult-diet, and artificial rearing. Ann. Ent. Soc. Amer., 69, 727-729.

ECONOMOPOULOS, A. P., AND ZERVAS, G. A. 1981. The quality problems in olive flies produced for SIT experiments. Proceedings, Int. Symp. on the Insect Control, Neuherberg, FR Germany, 29 June-3 July 1981. IAEA-SM-255/039 (in press).

FONTDEVILA. A. J., MENDEZ, J., AYALA, F. J., AND MCDONALD, J. 1975. Maintenance of allozyme polymorphisms in experimental populations of Drosophila. Nature, 255, 149151.

GELFAND, L. J., AND MCDONALD, J. F. 1980. Relationship between ADH activity and behavioral response to environmental alcohol in Drosophila. Behav. Genet., 10, 237-249.

JAIN, S. K., AND BRADSHAW, A. D. 1966. Evolutionary divergence among adjacent plant populations. I. The evidence and its theoretical analysis. Heredity, 21, 407-441.

KING, S. B., ROCKWELL, R. F., AND GROSSFIELD, J. 1976. Oviposition response to ethanol in D. melanogaster and D. simulans. Genetics, 83, 5-39.

KITTO, G. B., AND BRIGGS, M. H. 1962. Relationship between locomotory habits and enzyme concentration in insects. Science, $135,918$.

KRIMBAS, C. B. 1963. A contribution to the cytogenetics of Dacus oleae, Gmel. The salivary gland and mitotic chromosomes. Caryologia, 16, 371-376.

LOUKAS, M., KRIMBAS, C. B., AND VERGINI, Y. 1979. The genetics of Drosophila subobscura populations. IX. Studies on linkage disequilibrium in four natural populations. Genetics, 93, 497-523.

MCKENZIE, J. A., AND PARSONS, P. A. 1972. Alcohol tolerance: An ecological parameter in the relative success of Drosophila melanogaster and Drosophila simulans. Oecologia, $10,373-388$.

MUKAI, T., AND YAMAZAKI, T. 1980. Test for selection on polymorphic isozyme genes using the population cage method. Genetics, 96, 537-542.

O'BRIEN, S. J., AND MACINTYRE, R. J. 1972. The $\alpha$-glycerophosphate cycle in Drosophila melanogaster. I. Biochemical and developmental aspects. Biochem. Genet., 7, 141-161.

POULIK, M. D. 1957. Starch gel electrophoresis in discontinuous systems. Nature, 180, 1477.

PRAKASH, S., AND LEWONTIN, R. C. 1968, A molecular approach to the study of genic heterozygosity in natural populations. III. Direct evidence of coadaptation in gene arrangements of Drosophila. Proc. Natl. Acad. Sci. U.S., 54, 398-405.

REMUND, U., BELlER, E. F., ECONOMOPOULOS, A. P., AND TSITSIPIS, J. A. 1977. Flight performance of Dacus oleae reared on olives and artificial diet. Z. angew. Ent., 82, 330-339.

REMUND, U., ECONOMOPOULOS, A. P., BELLER, E. F., AGEE, H. R., AND DAVIS, J. C. 1981. Fruit fly quality monitoring: The spectral sensitivity of field-collected and laboratory reared olive flies, Dacus oleae Gmel. (Dipt., Tephritidae). Z. angew. Ent. (in press).

RICHMOND, R. C., AND GERKING, J. L. 1979. Oviposition site preference in Drosophila. Behav. Genet., 9, 233-241. 
ROBINSON, A. S., AND VAN HEEMERT, C. 1981. Genetic sexing in Drosophila melanogaster using the alcohol dehydrogenase locus and a $Y$-linked translocation. Theor. Appl. Genet., $59,23-25$.

SCHAFFER, H. E., YARDLEY, D. G., AND ANDERSON, w. w. 1977. Drift or selection: a statistical test of gene frequency variation over generations. Genetics, 87, 371-379.

SCHWARTZ, M., GERACE. L., O'DONNELL. J., AND SOFER, W. 1975. In Markert, C. (ed.) Isozymes, vol. I, Academic Press, New York, pp. 725-751.

STARMER, W. T., HEED. W. B., AND ROCKWOOD-SLUSS, E. S. 1977. Extension of longevity in Drosophila melanogaster by environmental ethanol: Differences between substrates. Proc. Natl. Acad. Sci. U.S., 74, 387-391,

TSAKAS, S.. AND ZOUROS, E. 1980. Genetic differences among natural and laboratory-reared populations of the olive-fruit fly Dacus oleae (Diptera: Tephritidae), Ent. exp. \& appl., $28,268-276$.

TSITSIPIS. J. A. 1977. An improved method for the mass rearing of the olive fruit fly, Dacus oleae (Gmelin) (Diptera: Tephritidae). Z. angew. Ent., 83, 919-926.

VAN DELDEN. W. BOEREMA. A. C., AND KAMPING, A. 1978. The alcohol dehydrogenase polymorphism in populations of Drosophila melanogaster. I. Selection in different environments. Genetics, 90, 161-191.

WRIGHT. S., AND DOBZHANSKY, TH, 1946. Genetics of natural populations. XII. Experimental reproduction of some of the changes caused by natural selection in certain populations of Drosophila pseudoobscura. Genetics, 31, 125-156.

zERVAS, G. A. 1977. Measuring sexual maturation in Dacus oleae. In Beller, E. F., and Chambers, D. L. (eds.) Quality Control. IOBC/WPRS, Bulletin 1975/5, pp. 121-122.

ZERVAS, G. A., AND ECONOMOPOULOS, A. P. 1981. Mating frequency in caged populations of wild and artificially reared (normal or gamma sterilized) olive fruit flies. Environ. Entomol. (in press). 